\title{
Hemispheric Asymmetry in Auditory Processing of Speech Envelope Modulations in Prereading Children
}

\author{
Sophie Vanvooren, ${ }^{1,2}$ Hanne Poelmans, ${ }^{1,2}$ Michael Hofmann, ${ }^{1}$ Pol Ghesquière, ${ }^{2}$ and Jan Wouters ${ }^{1}$ \\ ${ }^{1}$ Department of Neurosciences, ExpORL, and ${ }^{2}$ Parenting and Special Education Research Unit, University of Leuven, 3000 Leuven, Belgium
}

\begin{abstract}
The temporal envelope of speech is an important cue contributing to speech intelligibility. Theories about the neural foundations of speech perception postulate that the left and right auditory cortices are functionally specialized in analyzing speech envelope information at different time scales: the right hemisphere is thought to be specialized in processing syllable rate modulations, whereas a bilateral or left hemispheric specialization is assumed for phoneme rate modulations. Recently, it has been found that this functional hemispheric asymmetry is different in individuals with language-related disorders such as dyslexia. Most studies were, however, performed in adults and school-aged children, and only a little is known about how neural auditory processing at these specific rates manifests and develops in very young children before reading acquisition. Yet, studying hemispheric specialization for processing syllable and phoneme rate modulations in preliterate children may reveal early neural markers for dyslexia. In the present study, human cortical evoked potentials to syllable and phoneme rate modulations were measured in 5-year-old children at high and low hereditary risk for dyslexia. The results demonstrate a right hemispheric preference for processing syllable rate modulations and a symmetric pattern for phoneme rate modulations, regardless of hereditary risk for dyslexia. These results suggest that, while hemispheric specialization for processing syllable rate modulations seems to be mature in prereading children, hemispheric specialization for phoneme rate modulation processing may still be developing. These findings could have important implications for the development of phonological and reading skills.
\end{abstract}

Key words: auditory processing; auditory steady-state responses; children; dyslexia; hemispheric asymmetry; speech envelope

\section{Introduction}

Speech signals contain numerous auditory cues that contribute to speech perception, but the speech envelope is essential and with some limited spectral information almost sufficient for accurate speech intelligibility (Drullman et al., 1994; Shannon et al., 1995). The speech envelope is characterized by amplitude modulations (AM). Modulations $<50 \mathrm{~Hz}$ play an important role in the identification and segmentation of crucial speech units such as syllables (AM near $4 \mathrm{~Hz}$ ) and phonemes (AM near $20 \mathrm{~Hz}$ ) (Rosen, 1992). Theories about speech perception propose that these modulation ranges are processed asymmetrically in the auditory cortices, with a right hemispheric preference to process syllable rate modulations and a bilateral or left hemispheric preference to process phoneme rate modulations (Poeppel, 2003; Boemio et al., 2005). Moreover, this functional hemispheric asymmetry seems already present in infancy (Telkemeyer et al., 2009, 2011).

Received July 29, 2013; revised Dec. 16, 2013; accepted Dec. 18, 2013.

Author contributions: S.V., H.P., P.G., and J.W. designed research; S.V. performed research; M.H. contributed unpublished reagents/analytic tools; S.V., H.P., and J.W. analyzed data; S.V., H.P., P.G., and J.W. wrote the paper.

This research was supported by the Fund for Scientific Research Flanders (Grant G.0920.12) and the Research Council of KU Leuven (Grant 0T/12/044). H.P. is supported through the Research Fund KU Leuven (Grant PDMK/12/ 170). We thank all children and their families, as well as the teachers and schools that participated in this study. Special thanks are due to H. Luts for her useful comments; R. Luke for technical assistance; $S$. Dandache for support in the recruitment of participants; and to L. Gijbels, T. Goossens, and S. Magits for their assistance in data acquisition. The authors declare no competing financial interests.

Correspondence should be addressed to Sophie Vanvooren, 0\&N2, Herestraat 49, bus 721, 3000 Leuven, Belgium. E-mail: sophie.vanvooren@med.kuleuven.be.

DOI:10.1523/JNEUROSCI.3209-13.2014

Copyright $\odot 2014$ the authors $\quad 0270-6474 / 14 / 341523-07 \$ 15.00 / 0$
Recently, it has been suggested that a disturbance in this functional hemispheric asymmetry may be linked to language-related disorders such as dyslexia (Goswami, 2011). Developmental dyslexia is a neurological, hereditary disorder that is characterized by severe and persistent reading and spelling problems, which are thought to be caused by difficulties representing and manipulating the phonological structure of words at the syllable and/or phoneme level (Vellutino et al., 2004). Recent studies have suggested that deviances in the neural representation of speech envelope cues are related to these phonological problems. Hämäläinen et al. (2012) demonstrated that, compared with right hemispheric asymmetry in normal readers, individuals with dyslexia display a more symmetrical neural organization during syllable rate processing. Additionally, phoneme rate modulations are found to be less lateralized to (Lehongre et al., 2011) or reduced within (Poelmans et al., 2012a) the left hemisphere in individuals with dyslexia. On the other hand, some studies have shown auditory processing deviances in individuals with dyslexia already at the brainstem level (Hornickel et al., 2009).

However, most of these studies were performed in adults (Lehongre et al., 2011; Hämäläinen et al., 2012; Poelmans et al., 2012a) and school-aged children with dyslexia (Abrams et al., 2009), and little is known about how and when these neural alterations manifest in preschool children, before reading acquisition. Given that neural processing of syllable and phoneme rate modulations strongly relates to phonological awareness (Abrams et al., 2009; Lehongre et al., 2011; Poelmans et al., 2012a) and speech perception (Alaerts et al., 2009; Poelmans et al., 2012a), it 
Table 1. Participant characteristics

\begin{tabular}{lccc}
\hline & $\begin{array}{c}\text { HR group } \\
(N=34)\end{array}$ & $\begin{array}{c}\text { LR group } \\
(N=41)\end{array}$ & $p$ value \\
\hline Gender (F/M) & $15 / 19$ & $17 / 24$ & $0.999^{a}$ \\
Age (mo) & $62 \pm 3$ & $62 \pm 3$ & $0.490^{b}$ \\
Nonverbal IQ & $110 \pm 13$ & $111 \pm 10$ & $0.472^{b}$ \\
Parental educational level (low/middle/high) & $7 / 9 / 18$ & $10 / 16 / 15$ & $0.349^{a}$ \\
\hline
\end{tabular}

Values are given as mean $\pm S D$.

${ }^{a}$ Fisher's exact test.

${ }^{b}$ Paired $t$ test.

'Standardized scores with population mean ( mean $=100, S D=15)$.

may be that altered response patterns to these modulations in prereading children can predict reading problems before they occur.

To investigate this, auditory steady-state responses (ASSR) to syllable and phoneme rate modulations were measured in prereading children at high hereditary risk for dyslexia (based on first-degree relatives with official dyslexia diagnosis) and in prereading control children. We aimed to explore hemispheric response asymmetry for cortical syllable and phoneme rate modulations and to determine whether preschool children at high hereditary risk for dyslexia process syllable and/or phoneme rate modulations differently than control children. Furthermore, we aimed to examine processing at these cortical levels as well as processing at the brainstem level.

\section{Materials and Methods}

Participants. In this study, 87 5-year-old children (age range, 56-68 months), attending the last year of kindergarten, participated. All participants were monolingual Dutch speakers, without a history of brain damage, permanent hearing loss, or visual problems. Additionally, participants were required to have adequate nonverbal intelligence, defined by an IQ score of $>85$ on the Raven Coloured Progressive Matrices (Raven et al., 1984). Forty-four participants were children with an increased hereditary risk for dyslexia, the so-called high-risk (HR) group. These children had at least one first-degree relative (parent and/or sibling) with an official diagnosis of dyslexia, and consequently a greater risk for developing dyslexia (Gilger et al., 1991). The other 43 participants were control children, the so-called low-risk (LR) group. Children in the LR group had no family members with a learning or language deficit. HR and LR children were matched based on the following five criteria: (1) educational environment (same kindergarten school); (2) gender; (3) age; (4) nonverbal intelligence; and (5) parental educational level.

In the current report, 75 children ( 32 girls/ 43 boys) of this longitudinal study participated (Table 1). Twelve children in the larger cohort were excluded for the following reasons: (1) they were left handed, as assessed by the Edingburgh Handedness Inventory (Oldfield, 1971); or (2) they had moved excessively during the electroencephalography (EEG) recordings in all test conditions.

All tests were approved by the medical ethics committee of The University Hospitals Leuven. Written informed consent was obtained from parents along with verbal assent from the participating children. All children were tested between August and October at the start of third kindergarten.

Before the measurements, hearing thresholds and middle ear function were assessed by audiometric (pure-tone audiogram at $0.5,1,2$, and 4 $\mathrm{kHz}$ ), otoscopic and tympanometric examination. Four of 75 children experienced a mild temporary conductive hearing loss [pure tone average (PTA) at $0.5,1$, and $2 \mathrm{kHz}>20 \mathrm{~dB}$ HL: 22, 23, 24, and $25 \mathrm{~dB} \mathrm{HL}$ ] in the right ear due to ear infection or ear congestion at the moment of testing.

Neurophysiological stimulus and recording parameters. Neural sensitivity to auditory temporal cues was investigated by recording ASSR embedded in the EEG. ASSR measure the ability of the auditory system to fire synchronously to the rhythm (i.e., the modulation rate) of an auditory

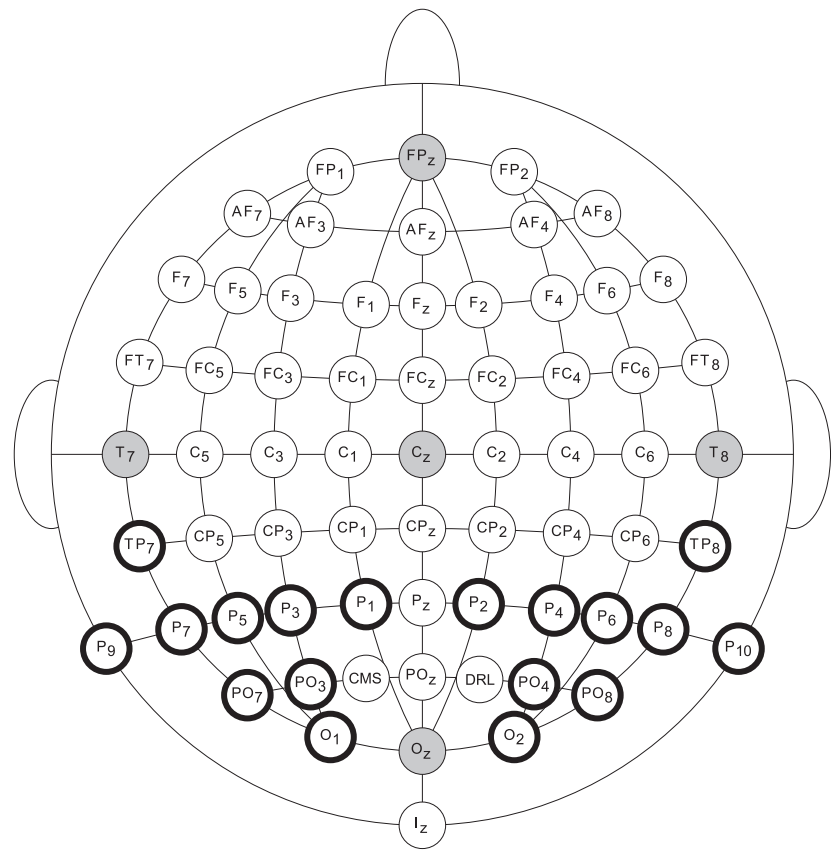

Figure 1. Electrode placement according to the 10-20 system for electrode positioning (Malmivuo and Plonsey, 1995). The bold circles indicate the electrodes used for analyses in this study.

stimulus (Picton et al., 2003; Picton, 2011). These responses can be recorded from cortical sources as well as from deeper sources such as the brainstem (Picton, 2011).

ASSR stimuli consisted of continuous amplitude-modulated, speechweighted noise. The noise carriers were derived from the speechweighted masking noise of the Leuven Intelligibility Sentence Test, which contains the long-term average speech spectrum of 730 sentences of a female speaker (van Wieringen and Wouters, 2008). Noises were 100\% amplitude modulated at modulation rates of 4,20 , and $80 \mathrm{~Hz}$. The first two modulation rates are known to be dominantly processed in the auditory cortex (Giraud et al., 2000) and can give important information on how syllable and phoneme units, respectively, in speech are processed in the brain. The $80 \mathrm{~Hz}$ modulation rate was selected as a reference condition, as it is shown in studies with latency and source waveform measurements that this rate dominantly gives information about modulation processing at the level of the brainstem (Herdman et al., 2002; Picton et al., 2003).

Stimuli were presented by an RME Hammerfall DSP Multiface multichannel soundcard in combination with stimulation platform RBA (Hofmann and Wouters, 2010) at a sampling rate of $32 \mathrm{kHz}$. Each stimulus was presented for $\sim 600 \mathrm{~s}$ with Etymotic Research ER-3A insert earphones, monaurally to the right ear at $70 \mathrm{~dB}$ SPL. For the four children with increased audiometric thresholds (PTA > $20 \mathrm{~dB} \mathrm{HL:} \mathrm{22,} \mathrm{23,} \mathrm{24,} \mathrm{and}$ $25 \mathrm{~dB} \mathrm{HL}$ ), the overall stimulation level was adjusted individually according to their PTA, with $+x \mathrm{~dB}$ for $x$, the PTA value $>20 \mathrm{~dB}$ HL. Hence, the sensation level was at least $50 \mathrm{~dB}$ SL for all children, and the maximum stimulation level was $75 \mathrm{~dB}$ SPL.

The continuous EEG was recorded from $64 \mathrm{Ag} / \mathrm{AgCl}$ active scalp electrodes, using ActiveTwo System software (Biosemi). The electrodes were mounted on a child-sized elastic head cap at the standard positions of the 10-20 system (Malmivuo and Plonsey, 1995; Fig. 1). The EEG recordings were conducted with a sampling rate of $8192 \mathrm{~Hz}$ and a recording bandwidth of DC-1600 Hz. The recordings were performed in a doublewalled and soundproof booth with a Faraday cage. During the measurements, children were lying on a bed for 3 blocks of $\sim 10$ min each while watching a soundless cartoon to stay awake. The cartoon was projected on a screen above the participant's head, providing a comfortable viewing experience. One test leader accompanied the child in the sound booth to comfort and instruct him/her, preventing excessive movement during measurements. 
$4 \mathrm{~Hz}$

EEG
Current
Source
Density

EEG Amplitude
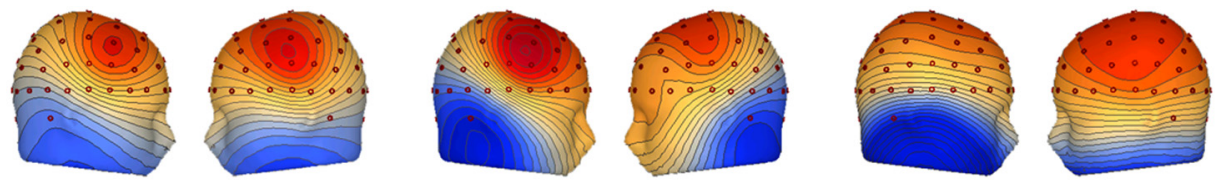

Figure 2. Topographical contour maps and time-domain waveforms for the grand mean averaged ASSR across all subjects for 4, 20, and $80 \mathrm{~Hz}$. Current source density maps (top) and amplitude voltage maps (middle) are plotted with reference-free interpolation and represent the maximum positive peak of the grand mean averaged response period. The electrode positions are indicated by red dots. Time-domain waveforms (bottom) are plotted with a Cz reference and represent the response to four cycles of the stimulus at channel P10.

Neurophysiological data analysis. Data analyses were performed offline in MATLAB R14 (MathWorks). The continuous EEG was divided into epochs of $1.024 \mathrm{~s}$. Epochs containing muscle artifacts (amplitude $>150 \mu \mathrm{V}$ ) were rejected using BESA research 5.3 software. To keep the number of analyzed epochs and the signal-to-noise ratio (SNR) equal across participants, only the first 448 artifact-free epochs for each participant in each condition were used. In 6 of the 75 children, $<448$ epochs remained after epoch selection for one ( 3 children) or two ( 3 children) of the three conditions due to excessive movement artifacts. More specifically, this was the case in a total of 9 measurements: 4,3 , and 2 of the 75 recorded measurements at 4,20 , and $80 \mathrm{~Hz}$, respectively. These data were excluded for further analyses, resulting in analyzed data of 71,72 , and 73 participants in total for the 4,20 , and $80 \mathrm{~Hz}$ conditions.

Analyses were performed on the electrode level since source waveform analyses were not possible due to a lack of good head models for surfaceto-source modeling in 5-year-old children. Data were referenced off-line to $\mathrm{Cz}$. The $\mathrm{Cz}$ reference was chosen over the average reference since it has been shown to be an appropriate reference electrode for laterality measurements and ASSR recordings in general (van der Reijden et al., 2005; Van Dun et al., 2009; Picton, 2011; Poelmans et al., 2012b). Moreover, a post hoc analysis with average reference demonstrated similar results. To avoid distortions caused by low drift and skin potentials, raw data were filtered by a $2 \mathrm{~Hz}$ zero-phase filter ( $12 \mathrm{~dB} /$ octave). For each recording, epochs were grouped into sweeps of 64 epochs, averaged in the time domain, and transformed into the frequency domain using a fast Fourier transform (FFT). After the FFT, the spectrum was corrected for the theoretical filter response to calculate accurate response estimates (see below).

Next, the signal-to-noise-ratio of the response (i.e., response SNR) was calculated (Eq. 1) based on the ratio between the power of the response plus noise at the tested modulation rate, $P(s+n)$, and the power of the noise estimate, $P(n)$, of 60 neighboring frequency bins on each side of the response frequency bin (corresponding in the response spectrum to $\sim 0.92 \mathrm{~Hz}$ to the left and right side of the modulation rate). A response was considered significant when the $F$ ratio statistic showed a significant difference $(p<0.05)$ between the power of the response plus noise and the power of the noise, corresponding to a response SNR of $4.8 \mathrm{~dB}$. Negative response SNRs were transformed to the baseline level of $0 \mathrm{~dB}$ (Alaerts et al., 2009; Poelmans et al., 2012a, 2012b).

$$
\text { response SNR }=10 \log _{10}[P(s+n) / P(n)] .
$$

Furthermore, hemispheric response asymmetry was calculated by a laterality index (LI; Eq. 2). The LI was based on the root mean square average of response amplitudes, $\mathcal{V}[P(s+n)-P(n)]$, of electrodes over the right $(\mathrm{R})$ and the left $(\mathrm{L})$ hemisphere. The LI was calculated as the difference between $\mathrm{R}$ and $\mathrm{L}$ normalized by the sum of $\mathrm{R}$ and $\mathrm{L}$. This measure reflects how strongly responses are lateralized to a specific hemisphere. The LI is +1 for a response completely asymmetrical to the right hemisphere, zero for a symmetrical response, and -1 for a response completely asymmetrical to the left hemisphere.

$$
\mathrm{LI}=(\mathrm{R}-\mathrm{L}) /(\mathrm{R}+\mathrm{L}) .
$$

Statistical analysis. For further analyses, an electrode selection was made based on two criteria. First, selection was based on the position of the electrodes on the scalp. In order to examine laterality, midline electrodes were excluded. Second, electrode selection was based on response recording sensitivity measured by the number of participants with significant responses on each electrode. The sensitivity for recording responses varied for different electrode positions. A high number of participants had significant responses on parietal and occipital electrodes. In contrast, the least number of significant responses was recorded at frontal electrodes with $<60 \%$ of significant responses in the majority of electrodes. Therefore, only electrode pairs of mirrored electrodes with an average number of significant responses of $>70 \%$ for all conditions were included.

Based on the above mentioned criteria, nine electrodes in the left hemisphere (TP7, P9, P7, P5, P3, P1, PO7, PO3, and O1) and nine electrodes in the right hemisphere (TP8, P10, P8, P6, P4, P2, PO8, PO4, and O2) remained for analyses (Fig. 1). Response SNRs were calculated for each of the above selected electrodes separately as well as averaged over the group of electrodes within each hemisphere. Accordingly, LIs were calculated for each electrode pair and for the paired group of electrodes.

Statistical analyses were performed with the SPSS version 20.0 (IBM). All analyses were two tailed $(\alpha=0.05)$. Normality of the response SNRs and LIs was tested by a Kolmogorov-Smirnov test separately for the participant groups and the modulation rates. For the latter test, the significance level was set at $\alpha=0.01$ to adjust for multiple comparisons. Response SNRs and LIs were normally distributed according to this criterion, except for the SNRs and LIs for the individual electrodes and electrode pairs. 


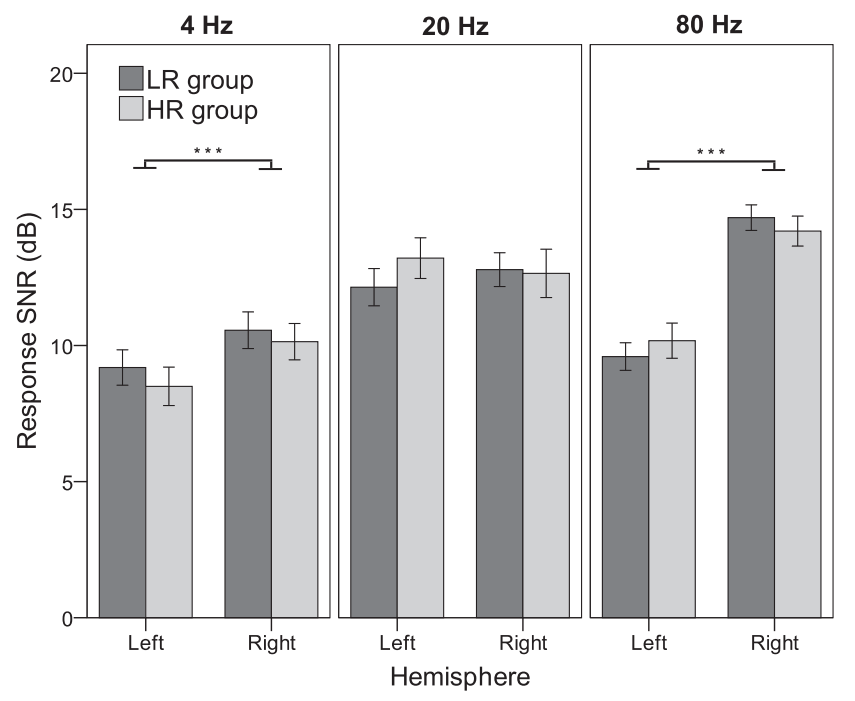

Figure 3. Average response SNR for LR (dark gray) and HR (light gray) children for 4, 20, and $80 \mathrm{~Hz}$. Bars represent the average response SNRs over nine electrodes from the left and right hemispheres. Error bars indicate mean \pm 1 SE. ${ }^{* *} p \leq 0.001$.

\section{Results}

The goal of this study was to investigate the cortical representation of slow temporal modulations in speech and to explore neural asymmetry to syllable and phoneme rate modulations in prereading children at high and low hereditary risk for dyslexia. Toward this end, neural speech envelope representations were investigated with response SNR values, and temporal processing asymmetry was examined with laterality indices.

Topographical maps of current source density, amplitude voltage, and time-domain waveforms for the grand mean averaged ASSR across all subjects for each condition are presented in Figure 2.

\section{Neural syllable and phoneme rate processing}

For the averaged response SNR over nine electrodes over each hemisphere, a repeated-measures ANOVA with group (HR vs LR) as a between-subject factor and hemisphere (left hemisphere vs right hemisphere) as a within-subject factor was conducted for the three tested modulation rates separately (Fig. 3).

For $4 \mathrm{~Hz}$, no main effect of group $\left(F_{(1,68)}=0.39, p=0.536\right)$ or interaction effect between group and hemisphere $\left(F_{(1,68)}=0.14\right.$, $p=0.707)$ was observed, suggesting no group difference in response SNR for the syllable rate. Overall, a main effect of hemisphere $\left(F_{(1,68)}=17.41, p<0.001\right)$ was found. Ipsilateral right hemisphere responses were higher than contralateral left hemisphere responses (mean difference, $1.5 \mathrm{~dB}$; SE, $0.4 \mathrm{~dB}$ ). This main effect of hemisphere was also found for individual electrodes with a Mann-Whitney $U$ test. For seven of nine electrode pairs, responses were significantly higher for right hemisphere electrodes than for left hemisphere electrodes (all $p<0.037$ ).

For $20 \mathrm{~Hz}$, no main effect of group $\left(F_{(1,69)}=0.23, p=0.631\right)$ or hemisphere $\left(F_{(1,69)}=0.01, p=0.911\right)$, nor an interaction $\left(F_{(1,69)}=2.52, p=0.117\right)$ between these factors was observed.

For $80 \mathrm{~Hz}$, no main effect of group $\left(F_{(1,70)}<0.01, p=0.946\right)$ or interaction effect between group and hemisphere $\left(F_{(1,70)}=\right.$ $3.03, p=0.086)$ was observed, suggesting no group difference in response SNR for the $80 \mathrm{~Hz}$ response. Overall, a main effect of hemisphere $\left(F_{(1,70)}=218.51, p<0.001\right)$ showed that ipsilateral right responses were considerably higher than contralateral left responses (mean difference, $4.6 \mathrm{~dB}$; SE, $0.3 \mathrm{~dB}$ ). This main effect

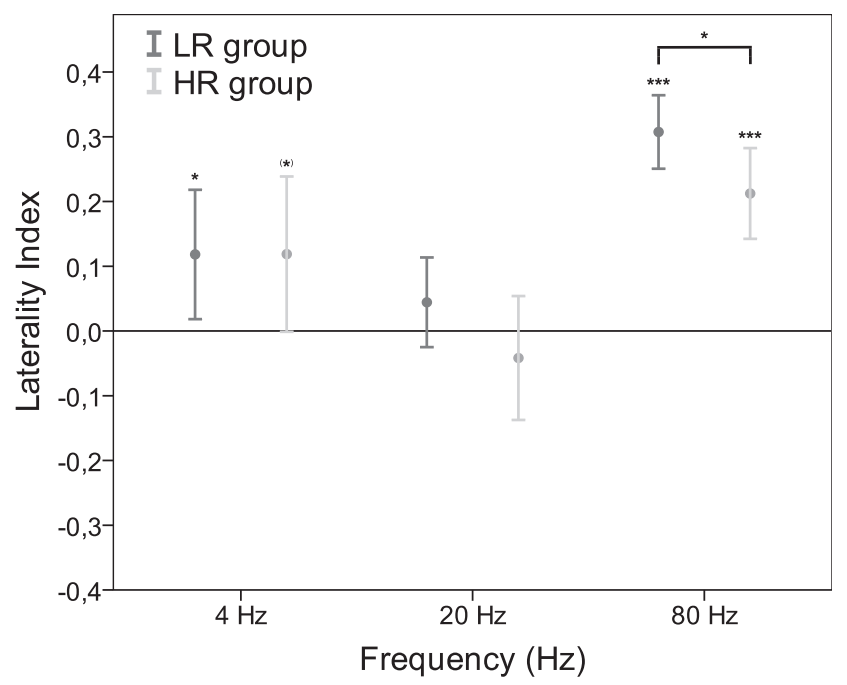

Figure 4. Mean LIs for LR (dark gray) and HR (light gray) children for 4, 20, and $80 \mathrm{~Hz}$. Error bars represent the $95 \%$ confidence interval of the mean. ${ }^{*} p=0.052,{ }^{*} p \leq 0.050,{ }^{* * *} p \leq$ 0.001 .

Table 2. Participants for each group (HR or LR) demonstrating left or right ASSR asymmetry for 4,20 , and $80 \mathrm{~Hz}$

\begin{tabular}{llccl}
\hline & Participants & Condition $(\mathrm{Hz})$ & Left $(\mathrm{LI}<0)$ & Right $(\mathrm{LI}>0)$ \\
\hline HR group & $n=31$ & 4 & $9(29)$ & $22(71)$ \\
& $n=32$ & 20 & $17(53)$ & $15(47)$ \\
LR group & $n=33$ & 80 & $2(6)$ & $31(94)$ \\
& $n=39$ & 4 & $11(28)$ & $28(72)$ \\
& $n=39$ & 20 & $17(44)$ & $22(56)$ \\
& $n=39$ & 80 & $1(3)$ & $38(97)$ \\
\hline
\end{tabular}

Values are given as №. (\%), unless otherwise stated.

of hemisphere was replicated at individual electrodes with a Mann-Whitney $U$ test. For all electrode pairs, right hemisphere responses were significantly higher than left hemisphere responses (for all electrode pairs, $p<0.001$ ).

\section{Temporal processing asymmetries}

To further examine the observed main effects of hemisphere, LIs were calculated. LIs were evaluated separately for each modulation rate and for each participant group based on a one-sample $t$ test for the averaged group of electrodes (Fig. 4) and based on a Wilcoxon signed-rank test for individual electrode pairs. To examine possible differences between the HR and the LR group, an independent sample $t$ test was conducted on the averaged group of electrodes, and a Mann-Whitney $U$ test was conducted on the individual electrode pairs.

To investigate laterality on a more individual level, participants were categorized according to their left $(\mathrm{LI}<0)$ or right $(\mathrm{LI}>0)$ asymmetric ASSR based on the LIs of the averaged group of electrodes (Table 2). Finally, a binomial test was conducted to examine whether a significant proportion of participants demonstrated left or right asymmetry.

For $4 \mathrm{~Hz}$, an ipsilateral right hemispheric asymmetry was found for the LR group ( $\left.\mathrm{LI}=0.12, t_{(38)}=2.40, p=0.022\right)$, and a trend toward right hemispheric asymmetry was found for the HR group $\left(\mathrm{LI}=0.12, t_{(30)}=2.40, p=0.052\right)$. This right hemispheric asymmetry was also present for the majority of the separate electrode pairs (LR group: five of nine electrode pairs, all $p<0.050$; HR group: eight of nine electrodes pairs, all $p<0.050)$ and for $>70 \%$ of the individuals within each participant group (LR 
group: $72 \%, z=2.72, p=0.001$; HR group: $71 \%, z=2.34, p<$ $0.001)$. No significant difference was found between the LR and HR group in the degree of right hemispheric asymmetry $\left(t_{(68)}=\right.$ $-0.01, p=0.995 ; U$ test: for eight of nine electrode pairs, $p>$ $0.050)$.

For $20 \mathrm{~Hz}$, responses were symmetrical for the LR group (LI = $\left.0.04, t_{(38)}=1.30, p=0.203\right)$ as well as for the HR group (LI $=$ $\left.-0.04, t_{(31)}=-0.89, p=0.380\right)$. Similarly, symmetrical responses were found for individual electrode pairs (LR group: seven of nine electrode pairs, all $p>0.050$; HR group: nine of nine electrode pairs, all $p>0.050$ ). For $20 \mathrm{~Hz}$, the number of participants with left asymmetry equaled the number of participants with right asymmetry in the LR group $(\mathrm{L}=44 \%, z=0.80$, $p=0.522)$ as well as in the HR group $(\mathrm{L}=53 \%, \mathrm{z}=0.35, p=$ $0.860)$. No significant group differences were found for $20 \mathrm{~Hz}$ $\left(t_{(69)}=1.51, p=0.135 ; U\right.$ test, all $\left.p>0.050\right)$.

Finally, a significant ipsilateral right asymmetry was found for $80 \mathrm{~Hz}$ for both participant groups for the averaged group of electrodes (LR group: $\mathrm{LI}=0.31, t_{(38)}=10.98, p<0.001$; HR group: $\left.\mathrm{LI}=0.21, t_{(32)}=6.17, p<0.001\right)$ as well as for individual electrode pairs (LR group: all $p<0.001$; HR group: all $p<0.001$ ). Right asymmetry was observed in $97 \%$ of the LR children $(z=$ 5.93, $p<0.001)$ and in 94\% of the HR children $(z=5.05, p<$ $0.001)$. A significant difference in the degree of asymmetry was found between the LR and the HR groups on the averaged group of electrodes $\left(t_{(70)}=2.16, p=0.034\right)$. This difference could, however, not be replicated on the level of individual electrode pairs ( $U$ test, all $p>0.050$ ).

\section{Discussion}

In the current study, cortical evoked potentials to syllable and phoneme rate modulations were measured in a group of prereading children with and without hereditary risk for dyslexia. Prereading children demonstrated a right hemispheric preference for processing syllable rate modulations. In contrast, symmetric processing of phoneme rate modulations was observed. No clear differences between the HR and the LR group could be observed.

In literature, evidence is reported for a functional hemispheric preference to process modulation rates that are present in the temporal envelope of speech (Poeppel, 2003). However, there is still no consensus about the precise manifestation of this hemispheric processing asymmetry. Whereas most studies indicate that syllable rate modulations are processed dominantly in the right hemisphere (Boemio et al., 2005; Abrams et al., 2008; Hämäläinen et al., 2012), it is still under debate as to whether phoneme rate modulations are processed in the left hemisphere (Abrams et al., 2008) or bilaterally (Boemio et al., 2005; Hämäläinen et al., 2012). An important factor contributing to these contradicting results is the methodological difference between studies. First, studies assessed asymmetry with different recording techniques (fMRI: e.g., Boemio et al., 2005; MEG: e.g., Hämäläinen et al., 2012; EEG: e.g., Poelmans et al., 2012a). Second, stimulus factors such as stimulus complexity (linguistic: e.g., Abrams et al., 2009; acoustic: e.g., Lehongre et al., 2011) or stimulus presentation manner (unilateral or bilateral stimulus presentation: e.g., Poelmans et al., 2012b) may have influenced hemispheric asymmetry. In a previous study, we investigated neural sensitivity to syllable and phoneme rate modulations in adults with and without dyslexia (Poelmans et al., 2012a,b) with exactly the same stimuli and a very similar recording technique as used in the present study. We found that, with right ear stimulation, syllable and phoneme rate modulations were lateralized to the right hemisphere (Poelmans et al., 2012b), and that adults with dyslexia demonstrate lower left hemispheric responses to phoneme rate modulations (Poelmans et al., 2012a). Based on these results, it was hypothesized that the literacy problems in dyslexia may be caused by a specific problem in processing phoneme rate modulations in the speech envelope.

In contrast to the results found in adults (Poelmans et al., 2012a), the present study did not find evidence for syllable and phoneme rate processing differences between preschool children with a high hereditary risk for dyslexia and control children. This is, however, not completely unexpected given the heterogeneity of the samples examined in this study. That is, the current study selected participants based on their hereditary risk for dyslexia. The fact that "only" up to $50 \%$ of the children with a high hereditary risk for dyslexia will eventually develop dyslexia (Gilger et al., 1991) implies that this high-risk group is very heterogeneous and that effects may be masked. Nevertheless, in previous fMRI studies, structural and functional alterations in posterior brain regions were demonstrated in children with high hereditary risk for dyslexia before reading onset (Raschle et al., 2011, 2012). Longitudinal follow-up and retrospective investigation of the current sample will be necessary to determine the real precursors of dyslexia.

In contrast to the syllable and phoneme rate modulations, a significant group difference was found for the $80 \mathrm{~Hz}$ control rate modulation in the absolute strength of lateralization. Since $80 \mathrm{~Hz}$ responses are known to be more prominent in the brainstem at the ipsilateral side of stimulation (see below), a lateralized processing was expected. However, responses at $80 \mathrm{~Hz}$ were significantly less lateralized to the right in HR compared with LR children. A less lateralized response in HR children may indicate reduced neural synchronization to the stimulus. Alternatively, it is possible that fewer brainstem neurons fire synchronously in the HR group compared with the LR group. However, the last two possibilities are unlikely, since no differences were found in absolute response SNR between HR and LR children. Moreover, the observed difference between the HR and LR group was present only for the averaged group of electrodes and could not be replicated when analyses were performed on the individual electrode pairs. This suggests that the group difference at $80 \mathrm{~Hz}$ may be a rather small effect. Nonetheless, in literature the presence of auditory processing abnormalities in individuals with dyslexia are found across multiple levels of the auditory processing system from the level of the auditory brainstem (e.g., Hornickel et al., 2009) to the level of the auditory cortices (e.g., Poelmans et al., 2012a). Moreover, Abrams et al. (2006) found that the precision of temporal encoding of speech in the auditory brainstem predicts cortical asymmetry to speech sounds. A poorer neural synchronization in the brainstem might thus influence the development of hemispheric asymmetry patterns at syllable and/or phoneme rate modulations.

Despite the lack of clear group differences, different hemispheric asymmetry patterns were found for the $80 \mathrm{~Hz}$ control rate, the syllable rate, and the phoneme rate modulations. For the $80 \mathrm{~Hz}$ control rate, a right lateralized response was found in the $\mathrm{HR}$ and LR groups. The dominant neural generators of the $80 \mathrm{~Hz}$ responses are located in brainstem, before the anatomical crossover of the auditory pathway in the superior olive complex (Picton et al., 2003), resulting in ipsilateral right lateralization to monaural right ear stimulation. Ipsilateral asymmetry to $80 \mathrm{~Hz}$ responses has been observed by others in adult studies as well as in children and infant studies (Herdman et al., 2002; Picton et al., 2003). 
For the syllable rate, responses were higher over the right than over the left hemisphere, for both the HR and the LR groups. Right asymmetry for syllable rate modulations was previously found in adults (Poelmans et al., 2012a,b), children (Abrams et al., 2009), and newborns (Telkemeyer et al., 2009, 2011). Together with the present findings, this suggests that right hemispheric specialization to process syllable rate modulations is already present at a very young age, possibly even from birth. This, in combination with the lack of group difference in the present study and in adults (Poelmans et al., 2012a), suggests that it is unlikely that the reading problems in dyslexia are caused by a neural deviance in processing syllable rate modulations.

For the phoneme rate, responses were equally high in both hemispheres, for both the HR and the LR groups. This is in contrast with results found in adults, where an ipsilateral preference (i.e., a right hemispheric asymmetry to right ear stimulation) for processing phoneme rate modulations was found (Poelmans et al., 2012b). The dissimilarity between both age groups may have structural as well as functional causes. First, the difference between children and adults may be due to a difference in the degree of cortical folding. If an extended range of pyramidal cells is activated, responses can be generated with a variable polarity due to the high folding that appears in the human cerebral cortex (Ahlfors et al., 2010). Depending on the local geometry of the cortex, this can result in a cancellation of the generated responses, especially when the patches of activity extend to opposite walls of sulci and gyri (Shaw et al., 2013). Furthermore, it has been shown that the degree of cortical folding changes with age and becomes stable only at 6-7 years of age (Nie et al., 2013). Therefore, a difference in the degree of cortical folding between hemispheres for children and adults in the region where responses to phoneme rate modulations are generated can cause different hemispheric response patterns at that rate. Second, it may be that the lateralization pattern of adults and prereading children differs because of developmental changes in the language network. Similar to the present results, Telkemeyer et al. $(2009,2011)$ found evidence for symmetrical processing of phoneme rate information in newborns. Given that cerebral lateralization changes with age (Shaw et al., 2009; Bishop, 2013) and that this development is influenced by maturation as well as experience (Minagawa-Kawai et al., 2011), it seems that symmetrical processing of phoneme rate modulations in prereading children develops into a specialized ipsilateral hemispheric preference, after the age of 5 years. This increasing cortical specialization for processing phoneme rate modulations may be linked to phonological and reading development. If phoneme rate processing mechanisms are not yet mature at the age of 5 years, this may explain why prereading children process phonological information at the syllable level, and do not spontaneously develop phoneme awareness before the start of reading instruction (Anthony et al., 2003; Ziegler and Goswami, 2005). It may be that a certain degree of cortical specialization is necessary to make this transition and to allow accurate reading development. Alternatively, it is possible that explicit reading instruction and the development of phoneme awareness has a top-down influence on the development of hemispheric specialization to process phoneme rate modulations in speech. Retrospective analysis of the current dataset, when children with dyslexia are identified, may unravel the causal nature of these hypotheses.

This study investigated cortical evoked potentials to syllable and phoneme rate modulations in a group of prereading children with and without hereditary risk for dyslexia. Even though we did not find group differences for processing syllable and phoneme rate modulations, the present results suggest an immature hemispheric specialization pattern for processing phoneme rate modulations in 5-year-old children. Therefore, it is hypothesized that a possible disturbance in the development of hemispheric specialization to processing phoneme rate modulations may, in part, underlie the reading problems of individuals with dyslexia. Longitudinal follow-up of these children will enlighten this assumption.

\section{References}

Abrams DA, Nicol T, Zecker SG, Kraus N (2006) Auditory brainstem timing predicts cerebral asymmetry for speech. J Neurosci 26:11131-11137. CrossRef Medline

Abrams DA, Nicol T, Zecker S, Kraus N (2008) Right-hemisphere auditory cortex is dominant for coding syllable patterns in speech. J Neurosci 28:3958-3965. CrossRef Medline

Abrams DA, Nicol T, Zecker S, Kraus N (2009) Abnormal cortical processing of the syllable rate of speech in poor readers. J Neurosci 29:7686-7693. CrossRef Medline

Ahlfors SP, Han J, Lin FH, Witzel T, Belliveau JW, Hämäläinen MS, Halgren E (2010) Cancellation of EEG and MEG signals generated by extended and distributed sources. Hum Brain Mapp 31:140-149. CrossRef Medline

Alaerts J, Luts H, Hofmann M, Wouters J (2009) Cortical auditory steadystate responses to low modulation rates. Int J Audiol 48:582-593. CrossRef Medline

Anthony JL, Lonigan CJ, Driscoll K, Phillips BM, Burgess SR (2003) Phonological sensitivity: a quasi-parallel progression of word structure units and cognitive operations. Read Res Q 38:470-487. CrossRef

Bishop DV (2013) Cerebral asymmetry and language development: cause, correlate, or consequence? Science 340:1230531. CrossRef Medline

Boemio A, Fromm S, Braun A, Poeppel D (2005) Hierarchical and asymmetric temporal sensitivity in human auditory cortices. Nat Neurosci 8:389-395. CrossRef Medline

Drullman R, Festen JM, Plomp R (1994) Effect of reducing slow temporal modulations on speech reception. J Acoust Soc Am 95:2670-2680. CrossRef Medline

Gilger JW, Pennington BF, DeFries JC (1991) Risk for reading disability as a function of parental history in three family studies. Read Writ 3:205-217. CrossRef

Giraud AL, Lorenzi C, Ashburner J, Wable J, Johnsrude I, Frackowiak R, Kleinschmidt A (2000) Representation of the temporal envelope of sounds in the human brain. J Neurophysiol 84:1588-1598. Medline

Goswami U (2011) A temporal sampling framework for developmental dyslexia. Trends Cogn Sci 15:3-10. CrossRef Medline

Hämäläinen JA, Rupp A, Soltész F, Szücs D, Goswami U (2012) Reduced phase locking to slow amplitude modulation in adults with dyslexia: an MEG study. Neuroimage 59:2952-2961. CrossRef Medline

Herdman AT, Lins O, Van Roon P, Stapells DR, Scherg M, Picton TW (2002) Intracerebral sources of human auditory steady-state responses. Brain Topogr 15:69-86. CrossRef Medline

Hofmann M, Wouters J (2010) Electrically evoked auditory steady state responses in cochlear implant users. J Assoc Res Otolaryngol 11:267-282. CrossRef Medline

Hornickel J, Skoe E, Nicol T, Zecker S, Kraus N (2009) Subcortical differentiation of stop consonants relates to reading and speech-in-noise perception. Proc Natl Acad Sci U S A 106:13022-13027. CrossRef Medline

Lehongre K, Ramus F, Villiermet N, Schwartz D, Giraud AL (2011) Altered low- $\gamma$ sampling in auditory cortex accounts for the three main facets of dyslexia. Neuron 72:1080-1090. CrossRef Medline

Malmivuo J, Plonsey R (1995) Bioelectromagnetism; Principles and applications of bioelectric and biomagnetic fields. New York: Oxford UP.

Minagawa-Kawai Y, Cristià A, Dupoux E (2011) Cerebral lateralization and early speech acquisition: a developmental scenario. Dev Cogn Neurosci 1:217-232. CrossRef Medline

Nie J, Li G, Shen D (2013) Development of cortical anatomical properties from early childhood to early adulthood. Neuroimage 76:216-224. CrossRef Medline

Oldfield RC (1971) The assessment and analysis of handedness: the Edinburgh inventory. Neuropsychologia 9:97-113. CrossRef Medline 
Picton TW (2011) Human auditory evoked potentials. San Diego: Plural Publishing.

Picton TW, John MS, Dimitrijevic A, Purcell D (2003) Human auditory steady-state responses. Int J Audiol 42:177-219. CrossRef Medline

Poelmans H, Luts H, Vandermosten M, Boets B, Ghesquière P, Wouters J (2012a) Auditory steady state cortical responses indicate deviant phonemic-rate processing in adults with dyslexia. Ear Hear 33:134-143. CrossRef Medline

Poelmans H, Luts H, Vandermosten M, Ghesquière P, Wouters J (2012b) Hemispheric asymmetry of auditory steady-state responses to monaural and diotic stimulation. J Assoc Res Otolaryngol 13:867-876. CrossRef Medline

Poeppel D (2003) The analysis of speech in different temporal integration windows: cerebral lateralization as "asymmetric sampling in time." Speech Commun 41:245-255.

Raschle NM, Chang M, Gaab N (2011) Structural brain alterations associated with dyslexia predate reading onset. Neuroimage 57:742-749. CrossRef Medline

Raschle NM, Zuk J, Gaab N (2012) Functional characteristics of developmental dyslexia in left-hemispheric posterior brain regions predate reading onset. Proc Natl Acad Sci U S A 109:2156-2161. CrossRef Medline

Raven JC, Court JH, Raven J (1984) Manual for Ravens's progressive matrices and vocabulary scales. London: Lewis.

Rosen S (1992) Temporal information in speech: acoustic, auditory and linguistic aspects. Philos Trans R Soc Lond B Biol Sci 336:367-373. CrossRef Medline

Shannon RV, Zeng FG, Kamath V, Wygonski J, Ekelid M (1995) Speech recognition with primarily temporal cues. Science 270:303-304. CrossRef Medline

Shaw ME, Hämäläinen MS, Gutschalk A (2013) How anatomical asymme- try of human auditory cortex can lead to a rightward bias in auditory evoked fields. Neuroimage 74:22-29. CrossRef Medline

Shaw P, Lalonde F, Lepage C, Rabin C, Eckstrand K, Sharp W, Greenstein D, Evans A, Giedd JN, Rapoport J (2009) Development of cortical asymmetry in typically developing children and its disruption in attentiondeficit/hyperactivity disorder. Arch Gen Psychiatry 66:888-896. CrossRef Medline

Telkemeyer S, Rossi S, Koch SP, Nierhaus T, Steinbrink J, Poeppel D, Obrig H, Wartenburger I (2009) Sensitivity of newborn auditory cortex to the temporal structure of sounds. J Neurosci 29:14726-14733. CrossRef Medline

Telkemeyer S, Rossi S, Nierhaus T, Steinbrink J, Obrig H, Wartenburger I (2011) Acoustic processing of temporally modulated sounds in infants: evidence from a combined near-infrared spectroscopy and EEG study. Front Psychol 1:62. CrossRef Medline

van der Reijden CS, Mens LH, Snik AF (2005) EEG derivations providing auditory steady-state responses with high signal-to-noise ratios in infants. Ear Hear 26:299-309. CrossRef Medline

Van Dun B, Wouters J, Moonen M (2009) Optimal electrode selection for multi-channel electroencephalogram based detection of auditory steadystate responses. J Acoust Soc Am 126:254-268. CrossRef Medline

van Wieringen A, Wouters J (2008) LIST and LINT: sentences and numbers for quantifying speech understanding in severely impaired listeners for Flanders and The Netherlands. Int J Audiol 47:348-355. CrossRef Medline

Vellutino FR, Fletcher JM, Snowling MJ, Scanlon DM (2004) Specific reading disability (dyslexia): what have we learned in the past four decades? J Child Psychol Psychiatry 45:2-40. CrossRef Medline

Ziegler JC, Goswami U (2005) Reading acquisition, developmental dyslexia, and skilled reading across languages: a psycholinguistic grain size theory. Psychol Bull 131:3-29. CrossRef Medline 